\begin{tabular}{|c|c|c|}
\hline 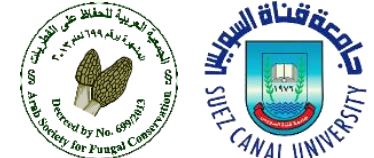 & $\begin{array}{c}\text { Contents lists available at Egyptian Knowledge Bank } \\
\text { Microbial Biosystems } \\
\text { Journal homepage: http://mb.journals.ekb.eg/ }\end{array}$ & $\begin{array}{l}\text { INTERNATIONAL SCIENTIFIC JOURNAL } \\
\text { OF MICROBIAL BIOLOGY }\end{array}$ \\
\hline
\end{tabular}

\title{
Fungi: The budding source for biomaterials
}

\section{Sunanda Mandal ${ }^{1}$, Remya Krishnan ${ }^{* 2}$}

${ }^{1}$ Department of Botany, University of Kalyani, West Bengal, India.

${ }^{2}$ Department of Botany, Kalindi College, University of Delhi-110008, India.

\section{ARTICLE INFO}

\section{Article history}

Received 23 August 2021

Received revised 4 September 2021

Accepted 5 September 2021

Available online 7 September 2021

(C) Mandal and Krishnan, 2021

Corresponding Editor:

Sridhar, K. R.

Simões Calaça, F. J.

Abdel-Azeem A. M.

\section{Keywords}

Mycelium

Construction

Pigments

Prebiotics

Medicine

Mushrooms

\begin{abstract}
In the last few decades, the demand for introducing biological resources into the multifaceted industry of medicine, food, cosmetics, textiles among others for manufacturing useful products has received immense consideration. Incidentally, fungal mycelium-based resources can act as an important instrument for the same. For example, cultivation of Ganoderma lucidum (Curtis)P. Karst. on a mixture which includes wheat straws and polypropylene embedded with spores from Bacillus amyloliquefaciens subsp. amyloliquefaciens resulted in a very unique biomaterial. This biomaterial is safe, inert, renewable, natural, biodegradable and could be molded in a desired shape. Also, they have high potential as thermal insulation material for applications in building sectors. Another example is of the billion-dollar cosmetic industry which seems to be in awe with byproducts of the fungal organisms for the development of antiaging products. A plus point with these fungal based products is that they are eco-friendly and are cost effective. These fungal organisms are extremely helpful in degrading the wastes produced by humans thus helping in curbing environmental contamination and also performing natural green auditing. This review is an attempt to emphasize the importance of mycelium-based bio-products in cosmetic, medicinal, packaging, enzyme, prebiotic, alkaloid, steroid, pigment, biopolymer, antibiotic, construction, vitamin based and organic acid industries.
\end{abstract}

Published by Arab Society for Fungal Conservation

\section{Introduction}

Fungi, especially the filamentous one, is now commonly acknowledged as the biological manufactures and have become vital in research and biotechnology. Fungal organisms such as mushrooms and truffles have conventionally been part of human diet majorly due to its flavour and protein content (Filho et al., 2019). In spite of its meagre production, the fungal single cell protein such as Fusarium venenatum Nirengberg, marketed under the title Quorn $^{\mathrm{TM}}$ has found its place in the market as a healthy substitute to meat, with its presence well established in the markets of Europe and USA (Filho et al., 2019). Many members of Ustilaginaceae like Ustilago maydis (DC.) Corda is used for production of multipurpose assortment of value-added substances with possible applications in the food, medicinal and chemical industry (production of succinate, itaconate, malate and erythritol) as mentioned by Geiser et al. (2014). Fungi are not only consumed as food but also used to produce stains, enzymes, antibiotics, vitamins, organic acids, prebiotics, polyunsaturated fatty acids, biofuel, detergents, packaging materials, cosmetics and so on (Meyer et al., 2016). Varied uses of filamentous fungi such as digestion of lignocellulosic materials and formation of entangled networks for mechanical strength opens new vistas of patent development (47 patents) in multiple fields of science and technology (Cerimi et al., 2019). Further, fungi have become indispensable in all field of making biomaterials thus can be called as magical mycelium (Haneef et al., 2017). Mycelium is composed of chitin, cellulose, proteins and many more natural polymers, hence can be termed as natural polymeric composite fibrous material 
(Zeller et al., 2012). Fungal mycelium is also be used as a binder or adhesive to hold together aggregates on desired objects thus becoming a cement replacement (Ross, 2017).

The fungal biotechnology possesses all probable reasons for supporting the food source to the world's half of the population in the form of vitamins, prebiotics and others while also concurrently decreasing greenhouse gas discharges in the environment. Moreover, fungi also play a critical positive impact towards environmental change and thus meeting the criterion of UN sustainability concept (Meyer et al., 2020). The filamentous fungi also have evolved to become highly resourceful decomposers (example, Crepidotus sp., Figure 1a) since they have the ability to feed on and break down organic matter and polymeric substances (Spatafora et al., 2017).

The fungal cells involved in saprophytic nutritional mode of absorption of the organic matter secretes numerous enzymes like cellulases, amylases, pectinases, proteases and lipases into the adjacent medium in order to hydrolyse the polysaccharides of the various flora (Cherry and Fidantsef, 2003). These fungi-based enzymes find multifaceted applicability in food, fodder, soap, paper, biofuel and medicinal as well as chemical industry among others to name a few (Meyer et al., 2020). Organic acids, like citric acid which is commercialized by the Pfizer, are also produced by these filamentous fungi using their fermentative capacities (Meyer et al., 2016). Further on to understand the versatility in metabolites production among the fungal kingdom, 66 strains of Ascomycetes and Basidiomycetes were tested and found to be involved in production of various organic acids including oxalic acid, formic acid among others. (Liaud et al., 2014). According to Meyer et al. 2020, many famous companies like Novozymes, AB enzymes, Bayer and others depend on these filamentous fungi for production of organic acids and bio-enzymes.

From biotechnological point of view, fungi, especially the Saccharomyces cerevisiae Meyen ex E.C. Hansen yeast, is involved in gene editing through CRISPR-Cas9 which helps in homologous targeting of exogenous DNA, thereby making it an experimental tool for biotechnological advancements (Idnurm and Meyer, 2018). Another ascomycetes advancement is on Aspergillus nidulans (Eidam) G.Winter has a c codon (Lb_cpf1) which has been optimized to be used for CRISPR based gene modification among the filamentous fungi (Vanegas et al., 2019).

\section{Applications of mycelium-based materials}

\section{Medicine}

Mushrooms have been used traditionally used for treating various ailments since ancient times (like the life-saving enigmatic Penicillin obtained in 1929 from Penicillium species). Majority of filamentous fungal species are known 56 for their therapeutic properties. The fruiting bodies of mushrooms and mycelia are rich in substances that work against virus, microbes, age related ailments. Additionally, they have anti-inflammatory, hypocholesterolemic and also have antioxidant properties (Gunawardena et al., 2014). The Basidiomycotina members like Agaricus Fr. ex Rabenh. contains immunostimulant properties which is helpful in medicinal world (Hobbs, 2003). Mushrooms (like Ganoderma sp., see Figure 1d) polysaccharides have a chemical composition including $\beta$-glucans linkages with $\beta$ $(1 \rightarrow 3)$ linkages as the main chain of the glucan and an additional $\beta-(1 \rightarrow 6)$ branch points which possess antitumor action (Wasser, 2002).

\section{Cosmetics}

The cosmetic industry involves topical creams and nutricosmetics and mainly deals with beauty products which are applied on the epidermal layer of the body. These creams should not only enhance the beauty but also should be safe for oral administration without any side-effects or irritation. For the development of beauty products, the products should be both effective and safe, hence the beauty industry is always on hunt for nature-based compounds owing to their efficiency and lower lethality. The probability of numerous fungal species has been reviewed and cherished as a traditional foundation for natural bioactive compounds (Hyde et al., 2010). Explicitly, Basidiomyctes (mushrooms) have numerous organic compounds (polyphenolics, polysaccharides, terpenoids, vitamins) which are useful for tresses and skin (Poucheret et al., 2006; Ahmad et al., 2013). These substances display excellent antiaging, anti-wrinkle and skin whitening effects to the skin (El Enshasy and HattiKaul, 2013; Kalač, 2013). For example, the Shiitake species of the mushroom sub-family are used as a skin exfoliator, which encourages rapid skin renewal and improves skin elasticity and brightness (Liu, 2002).

Various fungus-derived moisturizers improve the physical and chemical structure of the skin by making it soft, plump and healthy looking by nourishing the upper layer of the skin commonly known as epidermis and also by protecting the surface phospholipids (Sator et al., 2003). For instance, carboxymethylated polysaccharides attained from Tremella Linnaeus group of mushrooms hold around $65.7 \%$ of moistness even after 96 hours of its oral administration, thus helping to reduce the dryness of the skin (Wang et al., 2015). In a research it was found that, the presence of $0.05 \%$ Tremella polysaccharides as the constituent for skincare products had better moisture retention ability in comparison to $0.02 \%$ hyaluronic acid derived from snails (Liu and He, 2012). With the aging process, the skin loses its moisture retention ability which leads to disruption and collapsing of the elastin and collagen of the skin. Thus, to stop this there 

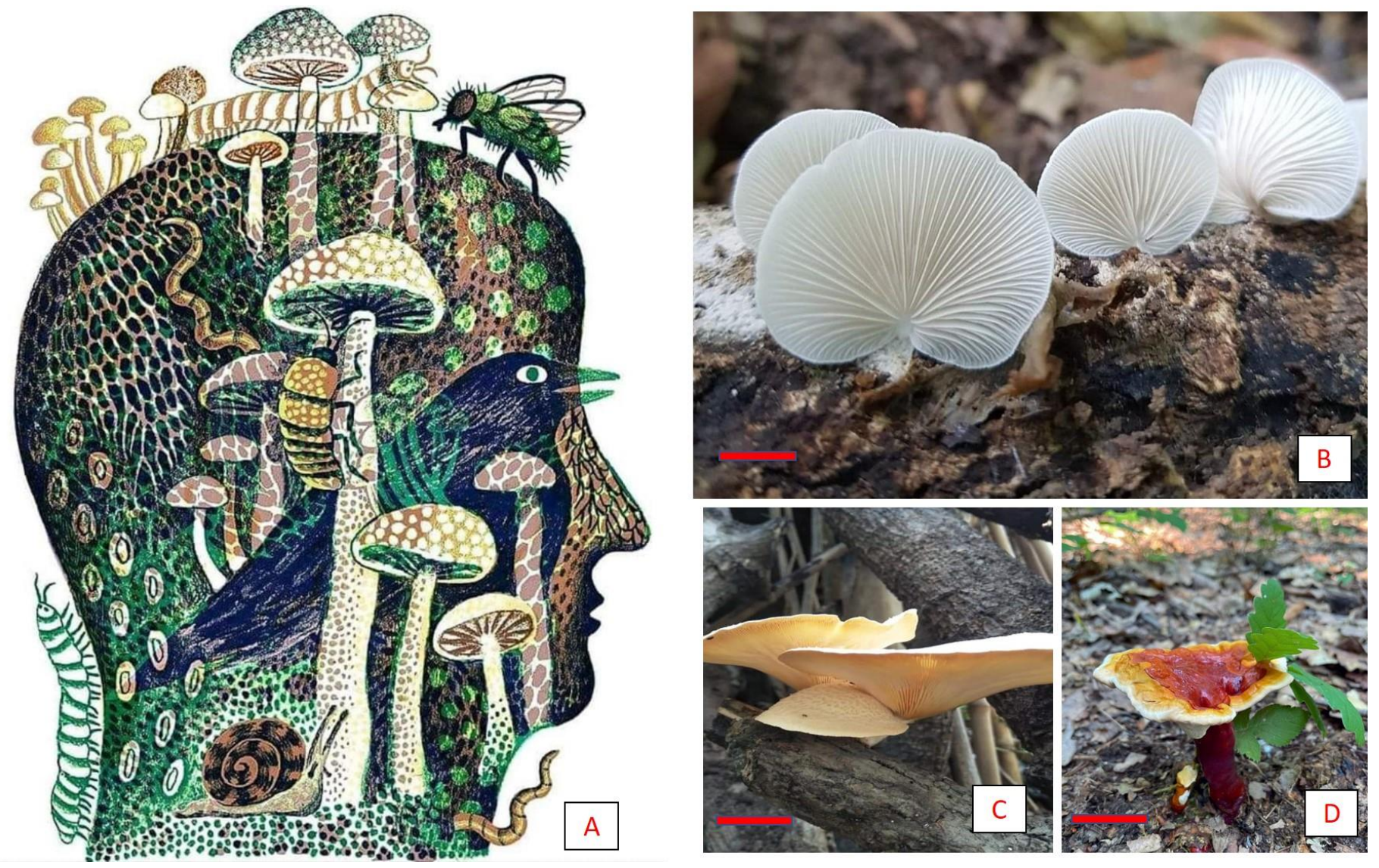

Fig 1. Fungi as biomaterials, A) Metaphorical image showing involvement of fungi as biomaterial. B) Crepidotus sp. used as a biodecomposers. C) Lentinus tigrinus shows antimicrobial and antioxidant activities. D) Ganoderma sp., a medicinally important mushroom. Scale Bars: $\mathrm{B}=0.2 \mathrm{~mm} ; \mathrm{C}$ and $\mathrm{D}=1 \mathrm{~mm}$

has been external application of antiaging products. Antiaging products including antioxidants like vitamin $\mathrm{C}$ that play an effective role in sustaining the body repair system (Lupo and Cole, 2007; Ocampo et al., 2016). A variety of fungi like Lentinula edodes (Berk.) Pegler, Volvariella volvacea (Bull.) Singer, Lentinus tigrinus (Bull.) Fr. (Figure 1C) and many more are a rich source of such antioxidants as well as biocatalysts, which has found applications in many skincare plus hair care products (Dubost et al., 2006; Keles et al., 2011). Further, a study by Tomiyama et al. (2008) testified that the extracts obtained from a mushroom (Pleurotus cornucopiae (Paulet) Rolland) can be orally administrated to mice which displayed constructive effects against a skin disease (atopic dermatitis). Yet another research finding showed that the extract from Pleurotus nebrodensis (Inzenga) Quél. aided the skin tone enhancer effect hence could be used as the bioactive constituent against skin discoloration, tanning etc. (Dangre et al., 2012). Correspondingly, bioactive substances obtained from mycelium of Ganoderma fromosanum T.T.Chang \& T.Chen decreased the surface pigmentation by impeding the tyrosinase enzyme (melanin growth promoter), responsible for cutaneous pigmentation (Hsu et al., 2016). In addition, there are numerous marine fungal species which displays inhibitory effects on tyrosine, thus can be potentially used in the preparation of skin whitening products (Lee et al., 2003).

A high concentration of extracellular melanin produced by Gliocephalotrichum simplex (J.A. Mey) B.J. Wiley \& E.G. Simmons showed efficient UV absorbance, demonstrating its possible usage as a constituent for sun protecting SPF creams (Jalmi et al., 2012). These studies propose that fungi can pave a new way into the cosmetic industry with its multifaceted applications. 


\section{Construction}

During the course of last few decades, accelerated growth of the cities stemmed the urgent need for supplying an uninterrupted reservoir of construction materials which include bricks, cement, insulation panels to the construction industry. However, the conventional building materials causes increase in pollution level in the atmosphere as well as require huge amount of energy for the production of the above-mentioned materials.

According to a study, for the production of an archetypal abode requires huge amount of vigour/energy (Sartori and Hestnes, 2007). The fungal mycelium byproducts and waste have attracted researchers for the production of low-energy construction materials as well as a new approach for waste recycling (Madurwar et al., 2013, Abhijith et al., 2018). Thus, the mycelium-based ingredients offer several benefits over outdated materials, including lowcost, biodegradability, and decreased environmental impact.

The application of broad range substrates in amalgamation with precise processing methods permits the construction of mycelium-derived resources with the anticipated structure and purpose for their apt use. The mycelium-based amalgams grow on straw and hemp fibers aid as a nature-based heat-protector due to low density and low thermal conductivity (Collet and Pretot, 2014), which usually have a strong linkage (Kadoya et al., 1985; Uysal et al., 2004). Moreover, fungal mycelium is dense and act as superb thermal insulators. The mycelium-based bio foams offer great possibility for application as substitute for other insulation materials used in edifice and infrastructure expansion (Yang et al., 2017).

Mycelium itself is an extraordinary acoustic absorber which displays a strong innate low-frequency absorption $(1500 \mathrm{~Hz})$ thus beating cork and which can potentially replace the conventional ceiling tiles to reduce the noise pollution. According to a study, the mycelium-based composites containing agricultural residues could display up to $70 \%-75 \%$ acoustic absorbance (Pelletier et al., 2013).

The fibers of the mycelium cause friction and restrict the audio wave motion; thus, they can possibly decrease its amplitude as the acoustic waves move through the convoluted routes of the material and are transferred to heat energy in the progression (Peters et al., 2013). Generally, the dense and compact materials absorb more sound energy as compared to the thin and relaxed materials. But here even thin mycelium fibers display better sound absorption and with the increase in number of fibers per unit volume results in increased twisting paths and aiding better air-flow resistance (Nor et al., 2014). The surface porosity and geometry of mycelium-based materials also display significant roles in sound absorbance (Samsudin et al., 2016).
The fungal mycelium-based amalgams also enjoy good fire safety attributes compared to traditional building materials such as polystyrene padding and particle-board. The mycelium also offer resistance against termites or wood digesting insects (Jones et al., 2019). The fungal myceliumbased materials are safe to use like the traditional high inflammable petroleum-based materials as the former produce less CO2 and smoke on burning (Jones et al., 2018). These unique attributes make the fungal mycelium-based amalgams as practical, value for money, safe for environment substitute in place of regular construction materials.

\section{Biopolymers}

Recently, various living organisms are introduced into the field of material science and nanotechnology which are broadly assessed for their capacity to produce biopolymers. Now-a-days, the concern of scientists is to produce materials that are biodegradable and cost-effective among other valuable features (Haneef et al., 2017). Hence for this purpose, mushroom mycelium is very obliging and valuable to use. The natural biopolymers such as chitin and cellulose are the major components of fungal mycelium and hence a biodegradable. Moreover, from the purification point of view fungal mycelium is far easier as compared with cellulose obtained from plant and other microbial origins. The mycelium films are easily purified by heating at $60^{\circ} \mathrm{C}$ for $2 \mathrm{~h}$ (Haneef et al., 2017), whereas the bacterial cellulose films need repeated washing with boiled sodium hydroxide solution followed by washing with sterilized water (Kim et al., 2019), while plant-based cellulose requires extensive physico-chemical and mechanical treatment for the removal of hemicellulose, lignin, and other impurities (Manan et al., 2021; Ullah et al., 2019). These two attributes make fungal mycelium an important candidate as biopolymer.

\section{Packaging}

In current scenario, due to globalization of the world's business which resulted in amplified demand for packaging supplies. The petroleum-derived polystyrene is presently the most searched packaging material; however, it is not biodegradable nor recyclable, thereby posing a serious threat to the environment. In addition to this, polystyrene is produced by high energy-consumable process and is not an eco-friendly option due to the emission of greenhouse gas. Thus, we can say it is dangerous to the environment. Thus, our fungal friends can offer solution to this problem (Cerimi et al., 2019). The mycelium-based materials due to their lightweight and non-toxic nature could be used as a wrapping or packaging materials for covering electronics, delicate items and food items. The green bio-composites obtained from fungi can be used as an alternative to conventional 
petroleum-derived packaging material in different fields (Ziegler et al., 2016). Fungal mycelium has the tendency to adopt the shape of the mould, thus making it a perfect candidate as packaging or wrapping material. Furthermore, with the help of controlled growth conditions and choice of substrate, it is conceivable to develop mycelium based wrapping substances of customized choices, density, and other structural attributes. A very well-known example is of a Chinese company where a mycelium-based packaging material was raised on the mould on wheat straw. The obtained biomaterial was lightweight, decomposable plus was also flexible (Cerimi et al., 2019).

In another alternative study by using Pycnoporus cinnabarinus (Jacq.) P.Karst., an orange-red packaging substance was created, which lacking any additional peripheral pigments. The obtained substance displayed high buoyancy, thus can be used for the manufacturing of sea buoys (Cerimi et al., 2019).

Furthermore, Joshi et al. 2020 reported the green synthesis of bio blocks by P. ostreatus (Jacq.) P. Kumm. where different agricultural wastes, such as wheat bran, sugarcane, sawdust, and a mixture of these materials were used. The synthesized material was aquaphobic and exhibited exceptional thermal and power-driven stability. This could find application in the field of wrapping as well as wall lining and also form filtration sheath for the removal of toxic substances (Joshi et al., 2020).

\section{Antibiotics}

Antibiotics by definition are the metabolic products produced by microbes which inhibits growth of other microbes. Sir Alexander Fleming (1929) was the first who invented the wonder drug Penicillin from Penicillium chrysogenum Thom., a breakthrough in the field of antibiotics. Now, Penicillin is commercially produced from $P$. chrysogenum Thom. Later on, other different types of antibiotics were isolated from different fungi (Delcambe ,1970). Although there are a large number of species of fungi, only few have been found to produce antibiotics, and only seven antibiotics are produced commercially. The 1970 Information Bulletin, No. 8 (Delcambe ,1970). of the International Center of Information on Antibiotics lists 338 species of fungi that produce antibiotics. According to Perlman and Bodanszey (1971), the following antibiotics are produced commercially: Fusidic acid formed by Fusidium coccineum Hickel, Griseofulvin formed by Penicillium griseofulvim Dierk, penicillins produced by Penicillium chrysogenum Thom, variotin formed by Paecilomyces varioti Bainier, derivatives of cephalosporin formed by Emericellopsis J.F.H.Beyma (Cephalosporium), and fumagillin produced by Aspergillus fumigatus Fres.. Also, siccanin produced by Helminthosporium siccans Drechsler has been commercialised in Japan.

\section{Alkaloid}

Numerous alkaloids are manufactured by the sclerotium of Claviceps purpurea Tul.Fr. which causes ergot disease of rye. Among the alkaloids Ergometrine and its semisynthetic analogues like methyl ergometrine and methyl ergometrine maleate having prominent uterine action which control haemorrhage of mother during child's birth. They however have side effects like increase in blood pressure and reduced milk secretion. Nevertheless, they are used in the pharmaceutical industry. Endophytic fungi are important source of drug production (Zhang et al., 2012, Dembitsky, 2014). Endophytic fungi are basically defined as fungi that spend the whole or part of their lifecycle inhabiting interand/or intra-cellularly inside the healthy tissues of the host plants, typically causing no apparent symptoms of disease. They are important components of plant micro-ecosystems and have been found in every plant species examined accounting to about one million fungal endophytes in nature (Daley and Cordell, 2021).

Endophytic group of fungi yield many secondary metabolites where alkaloids are one of them. Alkaloids are imperative molecules, not only because of their chemical properties but also for their diverse biological characters. They are also having antifungal, anti-cancerous and antiviral activities which is very important in today's world. Since the "gold" bioactive compound paclitaxel (taxol) was discovered from the endophytic fungus Taxomyces andreanae Strobel, A. Stierle, D. Stierle \& W. M. Hess from Taxus brevifolia Nutt. in 1993, many scientists have shown interests in studying fungal endophytes as potential producers for novel and biological active compounds (Stierle et al., 1993). Many compounds, for example, camptothecin, podophyllotoxin and hypericin, possesses a variety of biological activities, which were discovered successively from endophytic fungi from their host plants (Heinig et al., 2013).

\section{Steroids}

Some diseases namely Rheumatic arthritis and various types of allergies among others are controlled by the use of steroid and numerous fungi tends to produce these steroids. For example, cortisones are produced by Aspergillus niger Tiegh with the help of plant glycosides through fermentation (Chen et al., 2015).

\section{Vitamins and mucoproteins}

Micronutrients like vitamins are essential for the growth of living beings. Vitamin B-complex, Vitamin A and Vitamin B-12 are obtained from Saccharomyces cerevisiae (Desm.) 
Meyn, Rhodotorula gracilis Rennerf. and Eremothemium ashbyii Guillierm. respectively. Another important example where Clavatia gigantea (Batsch ex Pers.) Lloyd commonly known as giant puffball produces an anti-cancerous substance known as Calvacin that helps in prevention of stomach tumours (Strzelczyk and Leniarska, 1985). Likewise, Ganoderma lucidum (Curtis) P.Karst. a beautiful fungus seems to possess a promising substantial role in curbing cancerous growth, HIV and hepatitis-B ailments. Coriolus versicolor (L.) Pilat also possess ammunitions against malignant cancer (Strzelczyk et al.,1991).

\section{Enzymes}

Nearly half of the commercially utilized enzymes are of fungal origin due to their hydrolytic properties. The popular biocatalysts currently in use for the detergent industry are mainly the hydrolytic depolymerases. These includes various proteases and amylases in detergent preparations. In a strictly commercial sense, the main enzymes include protease, cellulase, xylanase, lipase, amylase, phytase among others produced by various different genera of microorganism including the fungal strains of Aspergillus P. Micheli ex Link, Rhizopus Ehrenb., and Penicillium E. M. Fries to name a few (Sunna and Antranikian, 1997; Maheshwari et al., 2000; Mondal et al., 2016).

\section{Organic acids}

Fungi, in particular genus Aspergillus have well known potential to produce a variety of organic acids. These microorganisms have an innate capacity to accumulate organic acids and it is generally assumed that this ability provides the fungi an ecological advantage (Porro and Branduardi, 2017). Since they have to tolerate acidic environmental conditions ( $\mathrm{pH} 3-5$ to 1.5). Organic acid production can be stimulated and in a number of cases where conditions are optimised, they convert large quantity of carbon substrate into acid. This property is thus used in comprehensive or mass production of a number of organic acids including citric, gluconic and itaconic acid to name a few. Citric acid produced by Aspergillus niger Tiegh. is the most important organic acid in terms of volume (Park et al., 2017). Other than citric acid, itaconic acid and gluconic acid are also of economic importance (Dezam et al., 2017).

\section{Fungi originated Prebiotic}

FOP (Fungi Originated prebiotics) can be traced in about 36,000 plants; however, the concentration of FOP in these sources is not enough to display prebiotics effects $(\mathrm{Wu}$, 2015). Therefore, FOP should be synthesized on a larger scale. Fructosyl-transferase (FTase) is a vital biocatalyst in manufacturing FOP. FTase manufactures FOP from sucrose by transporting one to three molecules to fructose. Numerous microbes have FTase, such as Fusarium sp., Aspergillus sp., Aureobasidium sp., Penicillium sp., Arthrobacter sp., Zymomonas mobilis (Lindner) Kluyver \& van Niel, Bacillus macerans Schardinger, Candida Berkhout, Kluyveromyces Walt, and Saccharomyces cerevisiae (Desm.) Meyen. Among the fungal group of organisms, Aspergillus niger Tiegh. and Aureobasidium pullulans (de Bary \& Löwenthal) G. Arnaud are frequently used in the FOP production (Lama, A., 2017).

For FOP production, the complete cell of a microbe or just the free enzyme can be used. There are numerous step regulators that affect the concentration of produced FOP (Chikkerur et al., 2018). The maximum quantity of FOP synthesised by FTases depends on the preliminary concentration of sucrose (theoretically around 55-60\%). Glucose produced during fermentation, constrains transglycosylation. Consequently, eliminating glucose and sucrose deposits is a crucial step to accomplish sophisticated harvests of FOP fermentation. Some researchers exploited glucose oxidase and $\beta$-fructofuranosidase to augment the harvest of FOP construction. $\beta$-fructofuranosidase has the ability to convert sucrose to FOP. The glucose formed via FOP fermentation is transformed to gluconic acid using glucose oxidase. In contrast to glucose, gluconic acid can be detached by ion-exchange resins or by coagulation with calcium carbonate. Thus, the utilization of both enzymes i.e glucose oxidase and $\beta$-fructofuranosidase upsurges the production of FOS formation up to $98 \%$. $\beta$ fructofuranosidase and glucose oxidase can be produced from Apostichopus japonicus Selenka and A. niger Tiegh., respectively. Glucose can be detached from FOP through nanofiltration methods. This method upsurges FOP manufacturing up to $90 \%$ (Muñiz-Márquez et al., 2019, Matei et al., 2017, Giorni, et al., 2018).

The two fungi namely $S$. cerevisiae (Desm.) Meyen. and Zymomonas mobilis (Lindner) Kluyver \& van Niel are capable to eradicate the minor carbohydrates, namely glucose, fructose, and sucrose, by changing saccharides to carbon dioxide and ethanol. They cannot ferment oligosaccharides with four or additional monosaccharide units. Sorbitol and FOP are also produced in small scale during fermentation of sucrose by Z. mobilis (Lindner) Kluyver \& van Niel (Belorkar, 2020).

\section{Pigments}

Pigments are basically the coloured compounds which are insoluble in water and are used for colouring food items. Filamentous fungi can be documented for manufacturing many astounding choices of pigments like carotenoids, melanins, flavins, phenazines, quinones, monascins, violacein, and indigo (Dufosse et al., 2014). The usage of 
Monascus Tiegh. for ang-kak (red mold rice) production is the oldest documented use of fungal pigment. Monascus yields yellow (ankaflavine, monascine), orange (rubropunctatine, monascorubrine), and purple (rubropunctamine, monascorubramine) coloured pigments which have found its importance in oriental foods, particularly in Southern China, Japan and Southeast Asia. Presently, more additives like 50 Monascus pigments have been recognized and looked upon. More than 50 patents across the globe have been dispensed regarding the use of Monascus stains in food items (Dufosse, 2016). Monascus pigments possess antimicrobial, antitumor, anti-mutagenic, and anti-obesity features which further helped the food industry for production of healthy food (Feng et al., 2012).

Supplementary, there are more than 200 fungal species documented for carotenes production (Dufosse, 2016). Zygomycetes for example are frequently involved in carotene production from the order Mucorales, which includes Phycomyces Kunze, Blakeslea Thaxt., and Mucor Linnaneus. In addition to Mucorales, carotene production has been reported in the basidiomycete's genera such as Rhodosporidium Banno, Sclerotinia Fuckel, Sporidiobolus Nyland, and Ustilago (Pers.) Roussel. Ascomycetes such as Aspergillus P. Micheli ex Link, Cercospora Fresenius, Penicillium E. M. Fries, and Aschersonia Montagne have also been reported as a source for carotenes manufacturing (Avalos and Limon, 2015).

Pigments such as anthraquinones, naphthaquinones, dihydroxy naphthalene melanin, flavin, anthraquinone, chrysophanol, cynodontin, helminthosporin, tritisporin, and erythroglaucin were reported by genera such as Eurotium Link, Fusarium Link, Curvularia Boedijn and Drechslera S. Ito (Babitha, 2009).

Recent literature has reported that marine organisms are involved in production of new pigments. Marine ecological niches have exceptional attributes like low temperature, absence of light, high pressure and salinity. Such conditions encourage nautical microbes to develop exceptional constituents (Dufosse, 2016). Genera such as Aspergillus P.Micheli ex Link , Penicillium E. M. Fries, Trichoderma Swainson, and Eurotium Link (Blaszczyk et al., 2014, Li et al., 2012, Dhale and Vijay Raj, 2009, Smetanina et al., 2007) have been described for pigment manufacturing. Marine derived fungal stains are like the terrestrial derived fungal dyes (Capon et al., 2007); but few pigments were produced solely by these nautical fungi. Like the yellow pigment (anthracene-glycoside asperflavin-ribofuranoside) manufactured by Microsporum sp. is found exclusive to this nautical-derived fungus ( $\mathrm{Li}$ et al., 2007).

Numerous marine-derived endophytic fungi like Aspergillus ruber (Jos.König, Spieck. \& W.Bremer) Thom \& Church, Halorosellinia Whalley, E. B. G. Jones, K. D. Hyde \& Læssøe, Hortaea Nishim. \& Miyaji, Phaeotheca
Sigler, Tsuneda \& J.W. Carmich., and Trimmatostroma Corda have been used for stain production (Dufosse et al., 2014). In-addition to plants, marine fungi also make close relationship with algae and corals. Reports suggest that marine endophytic fungi produce pigments that help to mimic and often increase the beauty of the associated life form (Dufosse et al., 2014). Fungus like Aspergillus E. M. Fries associates with coral skeleton (Porites lutea Milne Edwards \& Haime and Porites lobata Dana) and imparts black bands that are quite similar to the coral color (Priess et al., 2000).

Though numerous fungal stains have been described in the literature, they should essentially satisfy legal authorities in context to their lethality and constancy thus requires governing approval when produced commercially. These are required to bring the harvests from Petri dish to the marketplace (Malik et al., 2012). Though used for eras, numerous microbial stains are still prohibited in many countries. The best example is the Monascus Tiegh. pigment that has been used in Asia as a food dye but prohibited in Europe and United States due to the presence of probable fungal toxins in them (Dufosse et al., 2005). In this context, additional methods need to be developed for purification of these pigments.

\section{Leather like materials obtained from fungi}

Leather is a durable and flexible natural product that is produced by physical and chemical treatments (tanning) of animal skins and hides which alter their protein structure (China et al., 2020) Leather alternatives can be obtained from fungal mycelium i.e., the vegetative growth of filamentous fungi, which converts the low-cost agricultural and forestry by-products into chitinous polymers and other polysaccharides in a carbon-neutral biological growth procedure. Further on these chitinous polymer mats can be physically and chemically treated to produce fabrics that visually resemble both bovine and synthetic leather and exhibit comparable mechanical and tactile material properties (Haneef et al. 2017). Fungi-derived leather-like materials have a low environmental impact since its natural biological growth is used to produce chitinous polymers and other polysaccharides. Fungal mycelium is grown on lowcost forest-by-products, such as sawdust, before being physically and chemically treated to produce leather-like materials comparable appearance and materialistic properties to both bovine and synthetic leathers. They are primarily comprising chitin and other polysaccharides, such as glucans proteins, chitosan, polyglucuronic acid or cellulose (Jones et al., 2017, 2019). Therefore, these new leather-like materials are also fully biodegradable at the end of long service life, unless hybridized with other fabrics or polymeric materials, such as polyester and polylactic acid, in that case, 
biodegradability can be correlated to the least-easily degraded constituent.

\section{Conclusion}

The analysis of the biomaterial produced by fungi and their applications in different fields of science and technology, convincingly showed that this area belongs to a rapid growth sector. Starting with applications in the field of medicine, biomaterials produced by the fungi found its applicability into material science, cosmetology, leather industry to name a few. Filamentous fungi are usually termed as "production organisms" in biotechnology and have become indispensable in research and industry. Today, mushrooms and truffles are not only used as food items, but also the source of bioproducts which are actively used for biofuels and detergent production. Furthermore, the fungal bioactive compounds are also applied in veterinary and human medicine too. A survey claims that there are a total of 47 patents established from fungal biomass or fungal composite materials that are involved in the production of packaging, textile, leather and prebiotic materials. The future will show in what extend and in which areas fungal-based materials can replace current materials through their sustainable production ,re-use and exclusive properties. Hence, it is very clear that this field represents a great potential and has become a necessity for applied interdisciplinary research.

\section{Acknowledgements}

We would like to acknowledge the three unknown reviewers for their valuable suggestions. For name authority concerning taxa we would like to thank Prof. Paul Kirk the founder and owner of Index Fungorum (www.indexfungorum.org) for the unlimited support to all researchers worldwide.

\section{Conflict of Interest}

The authors declare that there is no conflict of interest.

\section{References}

Abhijith R, Ashok A Rejeesh CR (2018) Sustainable packaging applications from mycelium to substitute polystyrene: a review. Mater today: proceedings 5(1):21392145.

Ahmed YL, Gerke J, Park HS, Bayram Ö, Neumann P, Ni M, Dickmanns A, Kim SC, Yu JH, Braus GH Ficner R (2013) The velvet family of fungal regulators contains a DNA-binding domain structurally similar to NF- $\kappa$ B. PLoS biol. 11(12), p.e1001750.

Avalos J Limón MC (2015) Biological roles of fungal carotenoids. Curr. Genet. 61(3):309-324.
Babitha S (2009) Microbial pigments. In Biotechnology for agro-industrial residues utilisation (pp. 147-162). Springer, Dordrecht.

Belorkar SA (2020) Fungal Production of Prebiotics. In Fungal Biotechnology and Bioengineering (pp. 239-254). Springer, Cham.

Blaszczyk LMSKS, Siwulski M, Sobieralski K, Lisiecka J Jedryczka M (2014) Trichoderma spp.application and prospects for use in organic farming and industry. J. Plant Prot. Res. 54(4): 1-9.

Borriss R, Chen XH, Rueckert C, Blom J, Becker A, Baumgarth B, et al. (2011). Relationship of Bacillus amyloliquefaciens clades associated with strains DSM 7T and FZB42T: a proposal for Bacillus amyloliquefaciens subsp. amyloliquefaciens subsp. nov. and Bacillus amyloliquefaciens subsp. plantarum subsp. nov. based on complete genome sequence comparisons. Int. J. Syst. Evol. 61 (8): 1786-1801.

Capon RJ, Stewart M, Ratnayake R, Lacey E, Gill JH (2007) Citromycetins and bilains A-C: new aromatic polyketides and diketopiperazines from Australian marinederived and terrestrial Penicillium spp. J. 70(11):1746-1752.

Cerimi K, Akkaya KC, Pohl C, Schmidt B, Neubauer P (2019) Fungi as source for new bio-based materials: a patent review. Fungal boil. Biotechnol. 6(1):1-10.

Chen M, Wang KL, Liu M, She ZG, Wang CY (2015) Bioactive steroid derivatives and butyrolactone derivatives from a Gorgonian-derived Aspergillus sp. fungus. Chem. Biodiverse. 12(9):1398-1406.

Cherry JR, Fidantsef AL (2003) Directed evolution of industrial enzymes: an update. Curr. Opin. Biotechnol. 14:438-443.

Chikkerur J, Samanta AK, Dhali A, Kolte AP, Roy S, Maria P (2018) In Silico evaluation and identification of fungi capable of producing endo-inulinase enzyme. PloS one 13(7): p.e0200607.

China CR, Maguta MM, Nyandoro SS, Hilonga A, Kanth SV, Njau KN (2020) Alternative tanning technologies and their suitability in curbing environmental pollution from the leather industry: A comprehensive review. Chemosphere 254:126804.

Collet F, Pretot S (2014) Thermal conductivity of hemp concretes: Variation with formulation, density and water content. Constr. Build. mater. 65:612-619.

Daley SK, Cordell GA (2021) Biologically significant and recently isolated alkaloids from endophytic fungi. J. Nat. Prod. 84(3):871-897.

Dangre DM, Dafne LP, Bhagat RP, Chandekar CJ (2012) Effect of Pleurotus nebrodensis extract on melanin synthesis: A natural alternative for cosmetics. J. Medicinal Aromat. Plants 2:579-588. 
Delcambe L (1970) Infonnation Bulletin No.8. International Center of Information on Antibiotics, Etud'imprim, Liege, Belgium.

Dembitsky VM (2014) Naturally occurring bioactive Cyclobutane-containing (CBC) alkaloids in fungi, fungal endophytes, and plants. Phytomedicine 21(12):1559-1581.

Dezam AP, Vasconcellos VM, Lacava PT, Farinas CS (2017) Microbial production of organic acids by endophytic fungi. Biocatal. Agric. Biotechnol. 1(11):282-287.

Dhale MA, Vijay-Raj AS (2009). Pigment and amylase production in Penicillium sp NIOM-02 and its radical scavenging activity. Int. J. Food Sci. 44(12):24242430.

Dubost NJ, Beelman RB, Peterson D, Royse DJ (2006) Identification and quantification of ergothioneine in cultivated mushrooms by liquid chromatography-mass spectroscopy. Int. J. Med. Mushrooms 8(3):215-222.

Dufossé L (2016) Current and potential natural pigments from microorganisms (bacteria, yeasts, fungi, microalgae). In Handbook on Natural Pigments in Food and Beverages (pp. 337-354). Woodhead Publishing.

Dufosse L, Fouillaud M, Caro Y, Mapari SA, Sutthiwong N (2014) Filamentous fungi are large-scale producers of pigments and colorants for the food industry. Curr. Opin. Biotechnol. 26:56-61.

Dufossé L, Galaup P, Yaron A, Arad SM, Blanc P, Murthy KNC, Ravishankar GA (2005) Microorganisms and microalgae as sources of pigments for food use: a scientific oddity or an industrial reality? Trends Food Sci. Technol. 16(9):389-406.

El Enshasy HA, Hatti-Kaul R (2013) Mushroom immunomodulators: unique molecules with unlimited applications. Trends Biotechnol. 31(12):668-677.

Filho S, Pedro F, Dan A, Ferreira JA, Taherzadeh MJ (2019) Mycoprotein: environmental impact and health aspects. World J. Microbiol. Biotechnol. 35(10): 1-8.

Geiser E, Wiebach V, Wierckx N, Blank LM (2014) Prospecting the biodiversity of the fungal family Ustilaginaceae for the production of value-added chemicals. Fungal boil. Biotechnol. 1(1):1-10.

Giorni P, Pietri A, Bertuzzi T, Soldano M, Piccinini S, Rossi L, Battilani P (2018) Fate of mycotoxins and related fungi in the anaerobic digestion process. Bioresour. Technol. 265:554-557.

Gunawardena D, Bennett L, Shanmugam K, King K, Williams R, Zabaras D, Head R, Ooi L, Gyengesi E, Münch G (2014) Anti-inflammatory effects of five commercially available mushroom species determined in lipopolysaccharide and interferon- $\gamma$ activated murine macrophages. Food chem. 148:92-96.

Haneef M, Ceseracciu L, Canale C, Bayer IS, HerediaGuerrero JA, Athanassiou A (2017) Advanced materials from fungal mycelium: fabrication and tuning of physical properties. Sci. rep. 7(1):1-11.

Heinig U, Scholz S, Jennewein S (2013) Getting to the bottom of Taxol biosynthesis by fungi. Fungal divers. 60(1):161-170.

Hobbs C (2003) Medicinal mushrooms: an exploration of tradition, healing, and culture. Book Publishing Company, Botanica Press, US

Hsu KD, Chen HJ, Wang CS, Lum CC, Wu SP, Lin SP, Cheng KC (2016) Extract of Ganoderma formosanum mycelium as a highly potent tyrosinase inhibitor. Sci. rep. 6(1):1-9.

Hyde KD, Bahkali AH, Moslem MA (2010) Fungian unusual source for cosmetics. Fungal divers. 43(1):1-9.

Idnurm A, Meyer V (2018) The CRISPR revolution in fungal biology and biotechnology, and beyond. Fungal Biolog. Biotechnol. 5:1-4.

Index Fungorum (2021). www.Indexfungorum.org. accessed on 15 August 2021.

Jalmi P, Bodke $\mathrm{P}$, Wahidullah $\mathrm{S}$, Raghukumar $\mathrm{S}$ (2012) The fungus Gliocephalotrichum simplex as a source of abundant, extracellular melanin for biotechnological applications. World J. Microbiolog. Biotechnol. 28(2):505512.

Jones M, Bhat T, Huynh T, Kandare E, Yuen R, Wang $\mathrm{CH}$, John S (2018) Waste-derived low-cost mycelium composite construction materials with improved fire safety. Fire mater 42(7):816-825.

Jones M, Huynh T, Dekiwadia C, Daver F, John S (2017) Mycelium composites: a review of engineering characteristics and growth kinetics. J. Bionanosci. 11: 241257.

Jones M, Mautner A, Luenco S, Bismarck A, John S (2019) Engineered mycelium composite construction materials from fungal biorefneries: a critical review. Mater Des. 187: 108397-108413.

Joshi K, Meher MK, Poluri KM (2020) Fabrication and characterization of bioblocks from agricultural waste using fungal mycelium for renewable and sustainable applications. ACS Appl. Bio. Mater 3(4):1884-1892.

Kadoya K, Matsunaga N, Nagashima A (1985) Viscosity and thermal conductivity of dry air in the gaseous phase. J. Phys. Chem. Refer Data 14(4):947-970.

Kalač P (2013) A review of chemical composition and nutritional value of wild-growing and cultivated mushrooms. J. Sci. Food Agric. 93(2):209-218.

Keleş A, Koca I, Gençcelep H (2011) Antioxidant properties of wild edible mushrooms. Int. J. Food Process Technol. 2(6):2-6.

Kim Y, Ullah MW, Ul-Islam M, Khan S, Jang JH, Park JK (2019) Self-assembly of bio-cellulose nanofibrils through intermediate phase in a cell-free enzyme system. Biochem. Eng. J. 142:135-144. 
Lama A (2017) Screening of fungi with potential for producing fructooligosaccharides with enhanced bioactivity Polytechnic Institute of Bragança (Portugal).

Lee GT, Lee SY, Jeong JH, Jo BK, Li XF, Son BW (2003) PP-35 Screening of tyrosinase inhibiting activity from the marine-derived fungus. Pigment Cell Res. 16(5):604604.

Li G, He D, Qian Y, Guan B, Gao S, Cui Y, Yokoyama K, Wang L (2012) Fungus-mediated green synthesis of silver nanoparticles using Aspergillus terreus. Int. J. Mol. Sci. 13(1):466-476.

Li WC, Zhou J, Guo SY, Guo LD (2007) Endophytic fungi associated with lichens in Baihua mountain of Beijing, China. Fungal Divers. 25:.69-80.

Liaud N, Giniés C., Navarro D, Fabre N, Crapart S, Herpoël-Gimbert I, Levasseur A, Raouche S, Sigoillot JC (2014) Exploring fungal biodiversity: organic acid production by 66 strains of filamentous fungi. Fungal Biol. Biotechnol. 1(1):1-10.

Liu A, Hamel C, Elmi A, Costa C, Ma B, Smith DL (2002) Concentrations of $\mathrm{K}, \mathrm{Ca}$ and $\mathrm{Mg}$ in maize colonized by arbuscular mycorrhizal fungi under field conditions. Can. J. Soil Sci. 82(3):272-278.

Liu H, He L (2012) Comparison of the moisture retention capacity of Tremella Polysaccharides and Hyaluronic Acid [J]. J. Anhui Agric. Univ. 40:13093-13094.

Lupo MP, Cole AL (2007) Cosmeceutical peptides. Dermatol. Ther. 20(5):343-349.

Madurwar MV, Ralegaonkar RV, Mandavgane SA (2013) Application of agro-waste for sustainable construction materials: A review. Constr. Build. Mater. 38:872-878.

Maheshwari R, Bharadwaj G, Bhat MK (2000) Thermophilic fungi: their physiology and enzymes. Microbiol. Mol. Biol. Rev. 64(3):461-488.

Malik K, Tokkas J, Goyal S (2012) Microbial pigments: a review. Int. Journ. Microbiol. Res. and Technology 1(4):361-365.

Manan S, Ullah MW, Ul-Islam M, Atta OM, Yang G (2021) Synthesis and applications of fungal mycelium-based advanced functional materials. J. B. \& B. 6(1):1-10.

Matei GM, Matei S, Pele M, Dumitrescu F, Matei A (2017) Invertase production by fungi, characterization of enzyme activity and kinetic parameters. Rev. D. chim. (Bucharest) 68:2205-2208.

Meyer V, Andersen MR, Brakhage AA, Braus GH, Caddick MX, Cairns TC, de Vries RP, Haarmann T, Hansen K, Hertz-Fowler C, Krappmann S (2016) Current challenges of research on filamentous fungi in relation to human welfare and a sustainable bio-economy: a white paper. Fungal boil. Biotechnol. 3(1):1-17.

Meyer V, Basenko EY, Benz JP, Braus GH, Caddick MX, Csukai M, de Vries RP, Endy D, Frisvad JC, Gunde64
Cimerman N, Haarmann T (2020) Growing a circular economy with fungal biotechnology: a white paper. Fungal boil. Biotechnol. 7(1):1-23.

Mondal S, Baksi S, Koris A, Vatai G (2016) Journey of enzymes in entomopathogenic fungi. Pac. Sci. Rev. 18(2):85-99.

Muñiz-Márquez DB, Teixeira JA, Mussatto SI, Contreras-Esquivel JC, Rodríguez-Herrera R, Aguilar CN (2019). Fructo-oligosaccharides (FOS) production by fungal submerged culture using aguamiel as a low-cost by-product. LWT 102:75-79.

Nor MJM, Jamaludin N, Tamiri FM (2004) A preliminary study of sound absorption using multi-layer coconut coir fibers. e J. Tech. Acous. 3:1-8.

Ocampo A, Reddy P, Belmonte JCI (2016) Anti-aging strategies based on cellular reprogramming. Trends mol. Med. 22(8):725-738.

Park HS, Jun SC, Han KH, Hong SB, Yu JH (2017) Diversity, application, and synthetic biology of industrially important Aspergillus fungi. Adv. App. Microbiol. 100:161202.

Pelletier MG, Holt GA, Wanjura JD, Bayer E, McIntyre G (2013) An evaluation study of mycelium based acoustic absorbers grown on agricultural by-product substrates. Ind. Crops Prod. 51:480-485.

Perlman D, Bodanszey M (1971) Biosynthesis of peptide antibiotics. Annu. Rev. biochem. 40:449-464.

Peters RJ, Smith BJ, Hollins M (2013) Acoustics and noise control 3rd ed. New York: Taylor \& Francis Routledge.

Porro D, Branduardi P (2017) Production of organic acids by yeasts and filamentous fungi. In Biotechnology of yeasts and filamentous fungi Springer, Cham. (pp. 205-223).

Poucheret P, Fons F, Rapior S (2006) Biological and pharmacological activity of higher fungi: 20-year retrospective analysis. Cryptogam. Mycol. 27(4):311-333.

Priess K, Le Campion-Alsumard T, Golubic S, Gadel F, Thomassin B (2000). Fungi in corals: black bands and density-banding of Porites lutea and P. lobata skeleton. Mar. Biol. 136: 19-27.

Priest FG, Goodfellow M, Shute LA, Berkeley, RCW (1987) Bacillus amyloliquefaciens sp. nov., nom. rev. Inter. J. Syst. Evol. 37(1):69-71.

Ross P (2017) Fungal mycelium bio-materials. In Cultivated Building Materials, Berlin, Boston: Birkhauser 134-141

Samsudin EM, Ismail LH, Kadir AA (2016) A review on physical factors influencing absorption performance of fibrous sound absorption material from natural fibers. ARPN J. Eng. Appl. Sci. 11(6):3703-11.

Sartori I, Hestnes AG (2007) Energy use in the life cycle of conventional and low-energy buildings: A review article. Energy Build. 39(3):249-257. 
Sator PG, Schmidt JB, Hönigsmann H (2003) Comparison of epidermal hydration and skin surface lipids in healthy individuals and in patients with atopic dermatitis. J. Am. Acad. Dermatol. 48(3):352-358.

Smetanina OF, Kalinovskii AI, Khudyakova YV, Slinkina NN, Pivkin MV, Kuznetsova TA (2007) Metabolites from the marine fungus Eurotium repens. Chem. Nat. Compd. 43:395-398

Spatafora JW, Aime MC, Grigoriev IV, Martin F, Stajich JE, Blackwell M (2017) The fungal tree of life: from molecular systematics to genome-scale phylogenies. Microbiol. Spectr. 5:3-34.

Stierle A, Strobel G, Stierle D (1993) Taxol and taxane production by Taxomyces andreanae, an endophytic fungus of Pacific yew. Science 260(5105):214-216.

Strzelczyk E, Leniarska, U (1985) Production of Bgroup vitamins by mycorrhizal fungi and actinomycetes isolated from the root zone of pine (Pinus sylvestris L.). Plant Soil 86:387-394.

Strzelczyk E, Dahm H, Pachlewski R (1991) B-group vitamins production by mycorrhizal fungi in response to $\mathrm{pH}$ (in vitro studies). Plant Soil 137(2):237-241.

Sunna A, Antranikian G (1997) Xylanolytic enzymes from fungi and bacteria. Crit. Rev. Biotechnol. 17(1):39-67.

Tomiyama T, Kaihou S, Ishida M, Nishikawa H, Yamazaki N, Tsuji K, Mitsutake S, Igarashi Y (2008) The water retention effects and action for atopic dermatitis-like symptoms of ethyl alcohol extract (from tamogi-take [Pleurotus corncopiae var. citrinopileatus] mushroom) on animal model of atopic dermatitis. J. Jpn. Soc. Food Sci. Technol. 61(1):21-26.

Ullah MW, Shi Z, Shi X, Zeng D, Li S, Yang G (2017) Microbes as structural templates in biofabrication: study of surface chemistry and applications. ACS Sustain. Chem. Eng. 5(12):11163-11175.

Uysal H, Demirboğa R, Şahin R, Gül R (2004) The effects of different cement dosages, slumps, and pumice aggregate ratios on the thermal conductivity and density of concrete. Cem. Concr. Res. 34(5):845-848

Vanegas KG, Jarczynska ZD, Strucko T, Mortensen UH (2019) Cpf1 enables fast and efficient genome editing in Aspergilli. Fungal Biol. Biotechnol. 6:1-10.

Wang C, García-Fernández D, Mas A, Esteve-Zarzoso B (2015) Fungal diversity in grape must and wine fermentation assessed by massive sequencing, quantitative PCR and DGGE. Front. Microbiol. 6:1156-1164.

Wasser SP (2002) Medicinal mushrooms as a source of antitumor and immunomodulating polysaccharides. Appl. Microbiol. Biotechnol. 60(3):258-274.

Wu JY (2015) Polysaccharide-protein complexes from edible fungi and applications. Polysaccharides: Bioacty. Biotechnol. 31:927-937.
Yang Z (joey), Zhang F, Still B, White M, and Amstislavski P (2017) Physical and mechanical properties of fungal mycelium-based biofoam. J. Mater. Civil. Eng. 29(7):04017030.

Zeller P, Zocher D (2012) Ecovative's breakthrough biomaterials. Fungi Magazine 5: 51-56.

Zhang Y, Han T, Ming Q, Wu L, Rahman K, Qin L (2012) Alkaloids produced by endophytic fungi: a review. Nat. Prod. Commun. 7(7):963-968.

Ziegler AR, Bajwa SG, Holt GA, McIntyre G, Bajwa DS (2016) Evaluation of physico-mechanical properties of mycelium reinforced green biocomposites made from cellulosic fibers. App. Eng. Agric. 32(6):931-938. 